\title{
Biological nitrogen fixation detected under Antarctic sea ice
}

\author{
Takuhei Shiozaki ${ }^{1,2}$, Amane Fujiwara ${ }^{3}$, Keisuke Inomura ${ }^{4}$, Yuu Hirose ${ }^{5}$, Fuminori Hashihama ${ }^{6}$ and Naomi Harada ${ }^{2}$ \\ ${ }^{1}$ Atmosphere and Ocean Research Institute, The University of Tokyo, Chiba, Japan. ${ }^{2}$ Earth Surface System Research Center, \\ Japan Agency for Marine-Earth Science and Technology, Yokosuka, Japan. ${ }^{3}$ Institute of Arctic Climate and Environment \\ Research, Japan Agency for Marine-Earth Science and Technology, Yokosuka, Japan. ${ }^{4}$ School of Oceanography, University of \\ Washington, Seattle, WA, USA. ${ }^{5}$ Department of Applied Chemistry and Life Science, Toyohashi University of Technology, \\ Toyohashi, Japan. ${ }^{6}$ Department of Ocean Sciences, Tokyo University of Marine Science and Technology, Tokyo, Japan.
}

Nitrogen fixation is the primary source of reactive nitrogen in the ocean. Most ecological models do not predict nitrogen fixation in the Antarctic Ocean because of the low availability of iron and high abundance of nitrogen. In order to understand the characteristics of nitrogen fixation in the Southern Ocean, we observed at the stations along with the $110^{\circ} \mathrm{E}$ and $150^{\circ} \mathrm{E}$ lines and surrounding seas of Showa Base on the navigation root of the icebreaker SHIRASE, in $60^{\text {th }}$ Japanese Antarctic Research Expedition (Fig.1). Sampling was performed mainly onboard the icebreaker SHIRASE, except at some stations, where samples were collected from the beach area in the Skarvsnes and Langhovde areas of Antarctica, respectively. We extensively examined nitrogen fixation in the Antarctic Ocean, and found substantial nitrogen fixation (maximum: $44.4 \mathrm{nmol} \mathrm{N}^{-1} \mathrm{~d}^{-1}$ ) near the Antarctic coast, especially around ice-covered region. The nitrogenase gene (nifH) was detected at all coastal stations, including stations where no nitrogen fixation was found. At the stations where nitrogen fixation was detected, the nitrogenfixing cyanobacterium UCYN-A dominated nifH gene expression, and the nifH sequence was identical to that of the major oligotype in tropical and subtropical ocean. Our results suggest that marine nitrogen fixation is a ubiquitous process in the global ocean, and that UCYN-A is the keystone species for making it possible.

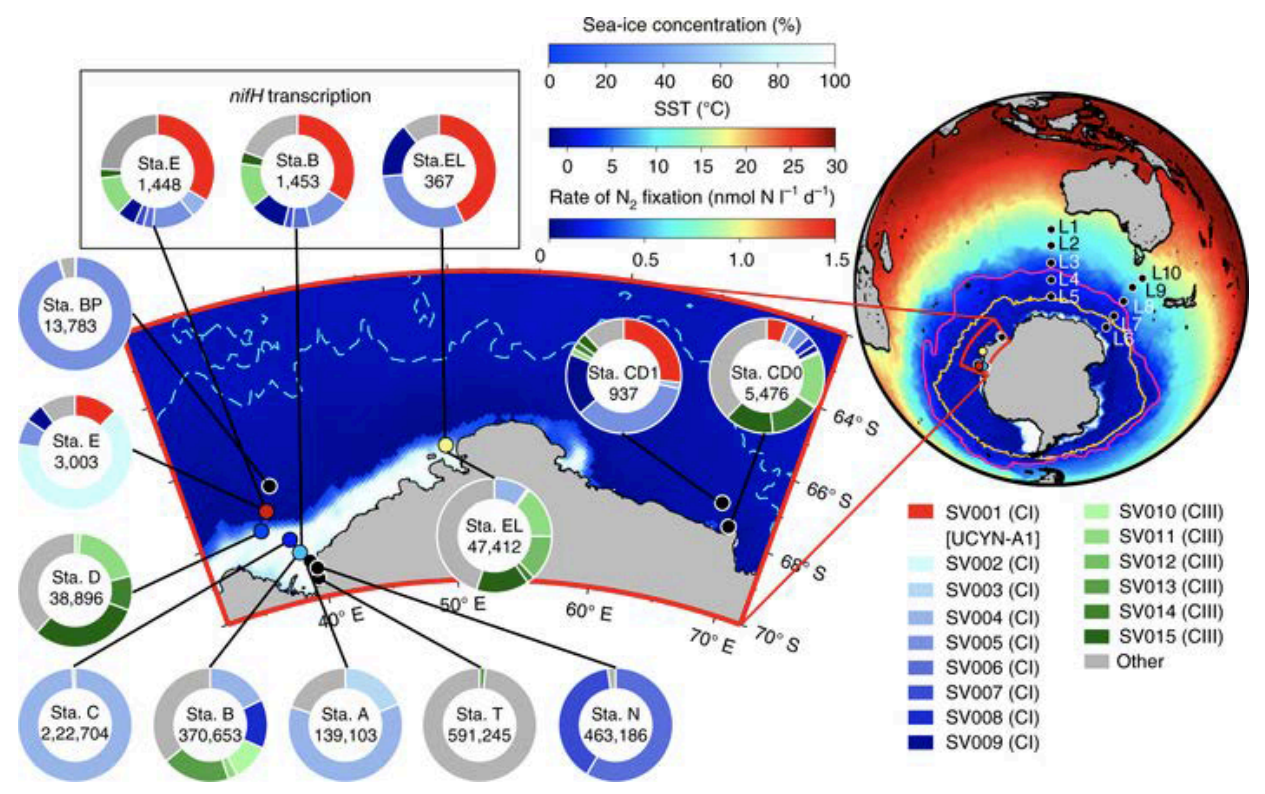

Fig. 1 Sampling stations, maximum nitrogen fixation and diazotroph community composition in the Antarctic Ocean. The colors of the circles in the map indicate the rate of nitrogen fixation (see the color scale, black indicates a result below the detection limit). The rate of nitrogen fixation at station $\mathrm{E}$ is above the upper limit of the color bar scale $\left(44.4 \mathrm{nmol} \mathrm{N}^{-1} \mathrm{~d}^{-1}\right)$. The number in each pie chart is the total sequence reads. The boxed pie charts (top left) show nifH transcription based on complementary DNA amplification. CI and CIII are Cluster I and Cluster III, respectively. The background shading indicates the sea-ice concentration measured by AMSR2 and sea surface temperature (SST) measured by OISST during the study period. The orange line shows the location of the ice edge when the ice content was maximal in 2018. The pink line shows the climatological location of the polar front (Orsi et al., 1995). The stations south of the polar front were classified into the permanent open ocean zone (stations L4 and L7), the seasonal ice zone (stations L5 and L8) and the coastal and continental shelf zone (CCSZ). The CCSZ was further classified into four regions: beach (stations $\mathrm{N}$ and T), fast-ice (stations A-C), ice-edge (stations D, E and EL) and ice-free (stations BP, CD0, and CD1). Dashed lines in the enlarged view around Antarctica denote the $0{ }^{\circ} \mathrm{C}$ isotherm of the sea surface temperature. Sta.,

\section{References}

Orsi, A. H., Whitworth, T. and Nowlin, W. D. On the meridional extent and fronts of the Antarctic Circumpolar Current. Deep Sea Res. Pt I 42, 641-673, 1995. 